\title{
The Properties of Wool-based Activated Carbon Tubes Prepared by Potassii with no Gas and Its Mechanism Study
}

\author{
Wen-Yang Tang, Chi-Yu Fu, Jia-xin Yu, Wu Chen* \\ State Key Engineering Laboratory for Advanced Textile Processing and Clean Production, Wuhan \\ Textile University, Wuhan 430200, China
}

\begin{abstract}
In this study, the wool-based activated carbon tubes (ACTs) were successfully prepared by potassii as additive. The ACTs had formed a tubular morphology with numerous pores located in both two sides. The mechanism of the tube formation were mainly investigated by removing overlapping scales on the surface of fibers and comparing the effects of experimental parameters. The removal method were carried out by formic acid and ultrasonic wave oscillation. The influence between scales and tubes was characterized by scanning electron microscopy (SEM), thermogravimetric analysis (TGA), methylene blue (MB) through discussing the morphology study, thermal property and adsorption capacity of ACTs. The surface morphology of the ACTs were affected by carbonization temperature, while the scale layers has no relations with the formation of a tubular morphology. Scale layers had almost no effects on thermal decomposition because close weight loss between ACKC2 and ACKC5. The adsorption capacity of ACTs from raw wool using two-step method is in the range of $18.50-26.75 \mathrm{mg} / \mathrm{g}$, which was obviously higher than using one-step method with $14.40-84.00 \mathrm{mg} / \mathrm{g}$. The adsorption capacity of ACTs decreased because of the removal of scale layers using one-step, which is contrary to ones using two-step.
\end{abstract}

Keywords: Activated Carbon Tubes; Wool Fibers; Scales Layers; Thermal Decomposition; Adsorption

\section{Introduction}

Activated carbon (AC), has been highly used because of its large specific surface area $\left(\mathrm{S}_{\mathrm{BET}}\right)$, high adsorption capacity and numerous pore structure, is a kind of non-polar carbon materials obtained through coal, wood and various biomass as precursor by a series of physical and chemical methods such as crushing, sieving, carbonization and activation [1,2]. The physical activation process is usually carried out by water steam, $\mathrm{CO}_{2}$ flow or chemical method by acid, alkali and salt [3-4]. And the carbonization process needs to be heat treated under protective gas flow like Ar or $\mathrm{N}_{2}$ flow. It has been used for catalyst, adsorbent [5], water purification [6], supercapacitors [7]. In addition to environmental protection, chemical medicine preparation and food preservation,

\footnotetext{
${ }^{*}$ Corresponding author.

Email address: wuchen@wtu.edu.cn (Wu Chen).
} 
it's also widely used in life, military and other fields [8, 9]. Another characteristic of AC is strong vapor adsorption capacity, which can be fully utilized [10]. There are some pores in the internal structure and active functional groups that can react with molecules on the surface. With stable chemical properties, activated carbon is heat resistant and does not react with acid or base. According to lots of researches, AC can be prepared with a wide range of raw materials, but traditional AC preparation mainly relies on wood and coal, which has caused a negative impact on the ecological environment [11]. With enhanced public awareness of environmental protection, researchers begin to study on some eco-friendly materials used for $\mathrm{AC}$ to reduce the hazardous effects [12]. Wool, a kind of proteinic fiber mainly constituted with $18 \alpha$-amino acids, has good features like chemical and mechanical properties, which can be used as textile materials [13]. Like other proteins, wool is a very active material [14]. It contains three main types of reactive groups: peptide bonds, amino acid side chains, and disulfide cross-linkings [15]. Chemicals which can react with wool include water, acid, alkali, reductant, oxidant, alkyl amine, formaldehyde, alcohol, anhydride, acyl chloride, and dye [16, 17]. The study on absorbability of wool with acid dyes demonstrates the possibility to remove the colorant from wastewater using AC [18]. Although traditional granular AC and powdered AC have their own advantages, the ACTs from wool fibers have the characteristics of small diameter and more concentrated pore distribution, which can effectively reduce diffusion limit and is favorable for rapid adsorption and desorption that adsorption capacity is higher at low concentration of adsorbents [19].

In this study, the waste wool from sweater or felt had been used to prepare ACTs showing a special hollow morphology, and the proper process, experimental parameters were also discussed in order to figure out the mechanism of the tubes formation. The removal of the scale layers will inevitably lead to the change of fiber properties. Therefore, the first step to study the mechanism is to remove the scale layer and then discuss its influence. This paper mainly compared the experimental conditions, for instance, the removal of scales, the concentration of activators, the carbonazation temperature and the methods. These parameters would all affect the preparation efficiency of ACTs and then marked the optimum experimental conditions. The morphology study, chemical content, thermal decomposition and adsorption behavior were tested and characterized by SEM, TGA and MB respectively. Also, some properties like yields, pore sizes, wall thicknesses were analyzed with the increasing temperature.

\section{Experiment}

\subsection{Materials}

Wool (leftovers from a sweater) with the diameter about $25 \mathrm{um}$, potassii (anhydrous pellets, AR grade, 99.0\% minimum purity), anhydrous formic acid (AR grade, 98.0\% minimum purity), distilled water, nitrogen gas, methylene blue (AR grade, 98.0\% minimum purity), Hydrogen squaminate disodium trihydrate, potassium dihydrogen squaminate, potassium squaminate, monopotassium phosphate.

\subsection{Fabrication of Activated Carbon Tubes}

In this study, the process of removing scale layers followed the method available in some researches. The method need to combined the physical and chemical steps together named formic acid and 
ultrasonic wave oscillation method. The anhydrous formic acid at the concentrate of $98 \%$ was boiled because it can be used for the dissolution of the wool fibers, and the destruction of the inter molecular hydrogen bonds of the stratum corneum. The boiled solution can lead to the expansion of the fiber bulk and then the edges of the scale layer would be curled or split. The activation process were followed by the soaking treatment with $\mathrm{K}_{2} \mathrm{CO}_{3}$ solution at different concentrations for 24 hours to improve the yields and strength of fibers. Then they were washed under running distilled water and dried at $60{ }^{\circ} \mathrm{C}$. Then pre-oxidation was conducted at a certain temperature at $260{ }^{\circ} \mathrm{C}$ which were recorded in some literature. Finally the wool fibers were carbonized under air, which resulted in thermal decomposition, condensation reaction and removal of volatile matter. Both in these two steps we need to sample some fibers every five minutes. And all samples were followed by drying at $60^{\circ} \mathrm{C}$ for $24 \mathrm{~h}$.

This experiment adopts one-step activation method and two-step method respectively. There are some obvious differences between the two processes with the gas flow, temperature, and additives. In one-step, the wool fibers were carbonized in the quartz tubular reactor embraced by a horizontal muffle under nitrogen flow or under air condition. They were heat-treated to $260{ }^{\circ} \mathrm{C}$ at a constant heating rate of $10{ }^{\circ} \mathrm{C} / \mathrm{min}$, where they were hold for $0.5 \mathrm{~h}$. After that, the activation process was followed by increasing to a higher activation temperature of $300{ }^{\circ} \mathrm{C}$ for 1 h. The apparatus was then switched off and cooled down to room temperature. The atmosphere condition is a variable and fibers were carbonized under nitrogen and air conditions respectively. The one-step activation conditions and sample identifications are summarized in Table 1.

Table 1: One-step activation conditions and sample identifications

\begin{tabular}{ccccc}
\hline Sample ID & Scale layers & Reagent concentration (wt.\%) & Heat rate $\left({ }^{\circ} \mathrm{C} / \mathrm{min}\right)$ & $\begin{array}{c}\text { Activation conditions } \\
\text { (gas) }\left({ }^{\circ} \mathrm{C}\right)(\mathrm{h})\end{array}$ \\
\hline ACK1 & Raw & $5 \%$ & 10 & $\mathrm{~N}_{2}, 300{ }^{\circ} \mathrm{C}, 1 \mathrm{~h}$ \\
ACK2 & Raw & $10 \%$ & 10 & $\mathrm{~N}_{2}, 300{ }^{\circ} \mathrm{C}, 1 \mathrm{~h}$ \\
ACK3 & Raw & $20 \%$ & 10 & $\mathrm{~N}_{2}, 300{ }^{\circ} \mathrm{C}, 1 \mathrm{~h}$ \\
ACK4 & isolated & $5 \%$ & 10 & Air, $300{ }^{\circ} \mathrm{C}, 1 \mathrm{~h}$ \\
ACK5 & isolated & $5 \%$ & 10 & Air, $400{ }^{\circ} \mathrm{C}, 1 \mathrm{~h}$ \\
ACK6 & isolated & $5 \%$ & 10 & Air, $500{ }^{\circ} \mathrm{C}, 1 \mathrm{~h}$ \\
ACK7 & Raw & $5 \%$ & 10 & Air, $300{ }^{\circ} \mathrm{C}, 1 \mathrm{~h}$ \\
ACK8 & Raw & $5 \%$ & 10 & Air, $400{ }^{\circ} \mathrm{C}, 1 \mathrm{~h}$ \\
ACK9 & Raw & $5 \%$ & 10 & Air, $500{ }^{\circ} \mathrm{C}, 1 \mathrm{~h}$ \\
\hline
\end{tabular}

In the process of two-step activation method, the raw wool and the wool isolated scale layers were heat-treated under nitrogen flow to $280{ }^{\circ} \mathrm{C}$ at a constant rate of $10{ }^{\circ} \mathrm{C}$ per minute respectively, and maintained for $1 \mathrm{~h}$. Simultaneously, thermal decomposition and condensation reaction took place to remove the volatiles of ash content and obtain carbonized wool char primarily. After cooling down the furnace to room temperature, the crude char was taken out and mixed with $\mathrm{K}_{2} \mathrm{CO}_{3}$ pellets at a ratio of $1: 2(\mathrm{w} / \mathrm{w})$. The chemical loaded samples were placed in the middle of the tubular reactor and then heat-treated from room temperature to 3 different activation temperatures $\left(400,500,600{ }^{\circ} \mathrm{C}\right.$ ) at a rate of $5^{\circ} \mathrm{C} / \mathrm{min}$ and held for $2 \mathrm{~h}$. In addition, the removal 
of scales is to eliminate the possible effect of scale on the tubular morphology of ACTs. The two-step activation conditions and sample identifications are summarized in Table 2.

Table 2: Two-step activation conditions and sample identifications

\begin{tabular}{cccccc}
\hline Stage and reagent & Sample ID & Scale layers & $\begin{array}{c}\text { Mixed ratio } \\
\left(\mathrm{K}_{2} \mathrm{CO}_{3} \text { : char values }\right)\end{array}$ & $\begin{array}{c}\text { Heat rate } \\
\left({ }^{\circ} \mathrm{C} / \mathrm{min}\right)\end{array}$ & $\begin{array}{c}\text { Activation conditions } \\
(\mathrm{gas})\left({ }^{\circ} \mathrm{C}\right)(\mathrm{h})\end{array}$ \\
\hline $\begin{array}{c}\text { First stage: carbonized } \\
\text { Second stage: }\end{array}$ & ACKC0 & Raw/isolated & & 10 & $\mathrm{~N}_{2}, 280{ }^{\circ} \mathrm{C}, 1 \mathrm{~h}$ \\
activated by $\mathrm{K}_{2} \mathrm{CO}_{3}$ & ACKC1 & Raw & $1: 2$ & 5 & $\mathrm{~N}_{2}, 400{ }^{\circ} \mathrm{C}, 2 \mathrm{~h}$ \\
& ACKC3 & Raw & $1: 2$ & 5 & $\mathrm{~N}_{2}, 500{ }^{\circ} \mathrm{C}, 2 \mathrm{~h}$ \\
& RCKC4 & isolated & $1: 2$ & 5 & $\mathrm{~N}_{2}, 600{ }^{\circ} \mathrm{C}, 2 \mathrm{~h}$ \\
& ACKC5 & isolated & $1: 2$ & 5 & $\mathrm{~N}_{2}, 400{ }^{\circ} \mathrm{C}, 2 \mathrm{~h}$ \\
& ACKC6 & isolated & $1: 2$ & 5 & $\mathrm{~N}_{2}, 500{ }^{\circ} \mathrm{C}, 2 \mathrm{~h}$ \\
& & & 5 & $\mathrm{~N}_{2}, 600{ }^{\circ} \mathrm{C}, 2 \mathrm{~h}$ \\
\hline
\end{tabular}

\subsection{Analytical Methods}

In this study, the investigation on the characteristics of wool-based ACTs mainly included four aspects: elemental analysis, morphology study, pore sizes, thermal properties and adsorption capacity. To determine the contents of $\mathrm{C}, \mathrm{H}, \mathrm{O}, \mathrm{N}, \mathrm{S}$, ash content of wool fibers and prepared ACTs, element analyses were performed by CMAS.

The morphology study of ACTs were observed by SEM, in which the real-time detection should be adopted in the process of removing scales from wool. The time of formic acid treatment and ultrasonic oscillation are two variables. After the treatment, fibers need to be sampled every 5 minutes as well and observed under SEM until the scale peeling degree reached $90 \%$, meanwhile keeping track of the time.

The average internal tube diameter $\left(\mathrm{D}_{\mathrm{T}}\right)$, fiber diameter $\left(\mathrm{D}_{\mathrm{F}}\right)$ and wall thickness $\left(\mathrm{T}_{\mathrm{W}}\right)$ of ACTs prepared from wool with a shape of tube by various treatment stages were measured through. The average, minimum and maximum values can be calculated by measuring each sample at least 50 times.

TG analyses were performed using a thermobalance under $\mathrm{N}_{2}$ flow of $30 \mathrm{ml} / \mathrm{min}^{-1}$ at a rate of $10{ }^{\circ} \mathrm{C} / \mathrm{min}$ and each sample need for testing was around $5.00 \mathrm{mg}$ and heated from $35^{\circ} \mathrm{C}$ to $800{ }^{\circ} \mathrm{C}$ until no further weight loss was detected.

The adsorption properties of ACTs in this paper were analyzed by their methylene blue (MB) adsorption. A certain concentration of methylene blue solution was placed in a set of $250 \mathrm{~cm}^{3}$ flasks in which equal masses of $0.1 \mathrm{~g}$ ACTs from different conditions were added. The solutions were adjusted to $\mathrm{pH}$ 7. Before being added to the flasks, the ACTs were crushed and sifted between $0.060 \mathrm{~mm}-0.080 \mathrm{~mm}$ in size. The ACTs were shaken mechanically and sampled at intervals of $1 \mathrm{~h}$ while its absorbance was observed until it became to a constant. The residual MB concentration in the solutions after adsorption was determined by Ultraviolet spectrophotometer, working at a fixed wavelength of $665 \mathrm{~nm}$. The mass of MB adsorbed by ACTs was obtained by converting the concentration of solution according to absorbance from Lamberbilt formula Eq. 


\section{Results and Discussion}

\subsection{Element Analyses}

Table 3 shows that contents of carbon and ash increase, in the char and ACTs samples, whereas the contents of hydrogen, nitrogen, oxygen and sulfur decrease. This is due to the release of volatiles and fracture of disulfide bond during heat-treated, which can result in the elimination of the non-carbon contents. As well, with the loss of $\mathrm{H}_{2} \mathrm{O}$ in carbonization process, the content of hydrogen and oxygen decrease gradually. This wool has a high carbon content of about $45.14 \%$, and a very low ash content of $0.07 \%$, which enables the formation of high specific surface area and high pore volume of ACTs.

Table 3: Element analyses of raw wool, char and ACTs activated by $20 \% \mathrm{~K}_{2} \mathrm{CO}_{3}$ at $400{ }^{\circ} \mathrm{C}$ by 2-step method

\begin{tabular}{cccc}
\hline Element & Raw wool (wt.\%) & Char (wt.\%) & ACTs (wt.\%) \\
\hline C & 45.14 & 65.49 & 69.12 \\
H & 6.72 & 4.10 & 3.79 \\
O & 29.47 & 20.78 & 18.43 \\
N & 15.11 & 8.14 & 7.28 \\
S & 3.49 & 1.08 & 0.73 \\
Ash content & 0.07 & 0.41 & 0.65 \\
\hline
\end{tabular}

\subsection{Morphology Study and Tube Sizes}

The Fig. 1 a shows that the wool fiber bulks were covered by overlapping scales on the surface. The three images prove that only combine the physical and chemical steps can totally remove the scale layers. But which step should be tested to figure out the properest time to avoid over treatment. Among several tests, it is confirmed that the formic acid treatment for $70 \mathrm{~min}$ combined with ultrasonic oscillation for $100 \mathrm{~min}$ is the best in this study.
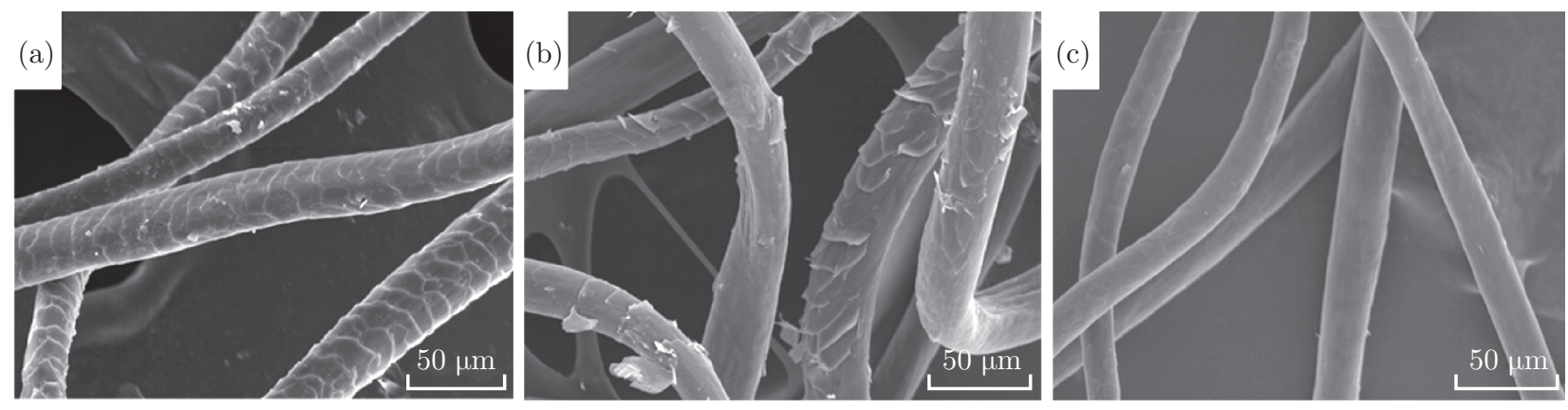

Fig. 1: SEM images of: (a) raw wool; (b) wool after formic acid treatment; (c) wool after formic acid combined with ultrasonic oscillation

The wool fibers without scale layers were obtained by above conditions and then used as precursors to prepare ACTs. From Fig. 2(a), it can be seen that the wool fiber are indeed solid 
structure. From SEM images in Fig. 2(b), (c), (d), they show that ACTs with tubes and pores can be prepared by one-step method under air condition and scales still exist on the surface of wool even heat-treated to a high temperature. It suggests that scales is very stable. Also, the quantity of ACTs increased with the increasing carbonization temperature. So the atmosphere and temperature are the main factors in this study on the formation of tubes.

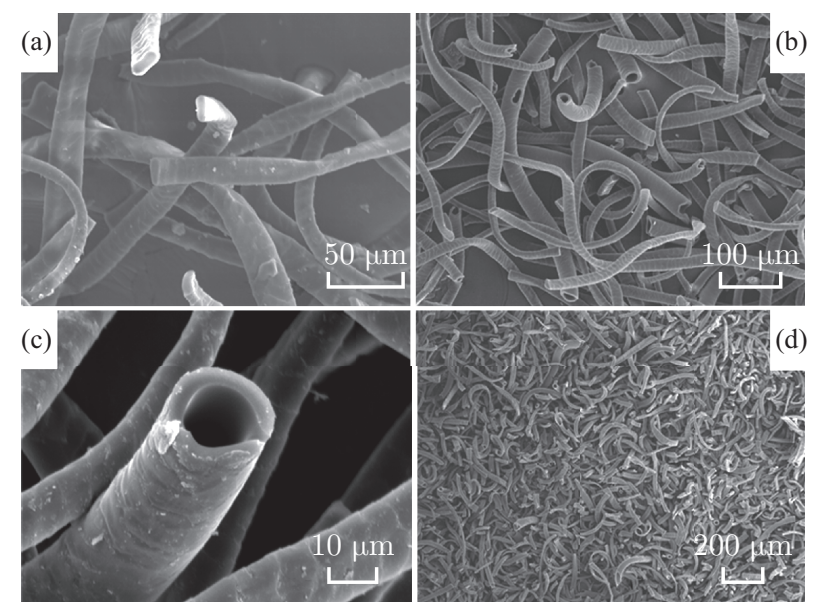

Fig. 2: SEM images of: (a) raw wool; (b) ACTs from wool isolated scales activated by $5 \% \mathrm{~K}_{2} \mathrm{CO}_{3}$ at $300{ }^{\circ} \mathrm{C}$ under air; (c) $400{ }^{\circ} \mathrm{C}$; (d) $500{ }^{\circ} \mathrm{C}$

Table 4 illustrates how the two factors, carbonization temperature, and scale layers, act on the tube size and wall thickness. Carbonized at different temperature but activated by same regents and method, ACK4, ACK5 and ACK6 show that the values of yields, $\mathrm{T}_{\mathrm{W}}$ and $\mathrm{D}_{\mathrm{T}}$ all decreased with the increasing temperature. Also, the results shows that the removal of scale layers almost have very little impacts on these property because these values are very closed by comparing ACK4 and ACK7. So tube-size and wall-thickness can be controlled by adjusting the parameter, carbonization temperature.

Table 4: Yields, tube sizes and wall thickness of ACTs

\begin{tabular}{cccc}
\hline Sample ID & Yields (wt. \%) & $\mathrm{T}_{\mathrm{W}}(\mathrm{um})$ & $\mathrm{D}_{\mathrm{T}}(\mathrm{um})$ \\
\hline ACK4 & 0.512 & 4.517 & 23.185 \\
ACK5 & 0.346 & 3.902 & 18.503 \\
ACK6 & 0.091 & 2.936 & 10.729 \\
ACK7 & 0.537 & 4.709 & 22.905 \\
ACK8 & 0.367 & 3.814 & 19.103 \\
ACK9 & 0.072 & 3.036 & 11.729 \\
\hline
\end{tabular}

\subsection{Thermogravimetric Analysis (TGA)}

The TGA analyses of ACKC2, ACKC5 and wool fibers are presented in Fig. 3. From the TGA of raw wool, it can be seen that, between $0{ }^{\circ} \mathrm{C}$ to $100{ }^{\circ} \mathrm{C}$, there was a loss of $7.46 \%$ of the initial mass in relation to the elimination of moisture from sample. At temperatures between $100{ }^{\circ} \mathrm{C}$ to $280{ }^{\circ} \mathrm{C}$ (the process of pre-oxidated), it shows a big loss about $31.52 \%$. Especially at $312.1{ }^{\circ} \mathrm{C}$, 
the themogravimetric slope changed significantly, indicating the beginning of the carbonization process occurred. It caused by the vaporization of the volatile compounds. The TGA of ACKC2 and ACKC4, it shows smaller mass loss than raw wool. The themogravimetric slope changed a little and shows the weight loss about $20 \%$ at $800{ }^{\circ} \mathrm{C}$, resulting in a solid residue without volatile compounds.As well, seen from these two lines of ACKC2 and ACKC5, the results of scale layers having almost no effects on thermal decomposition can be found in Fig. 3.

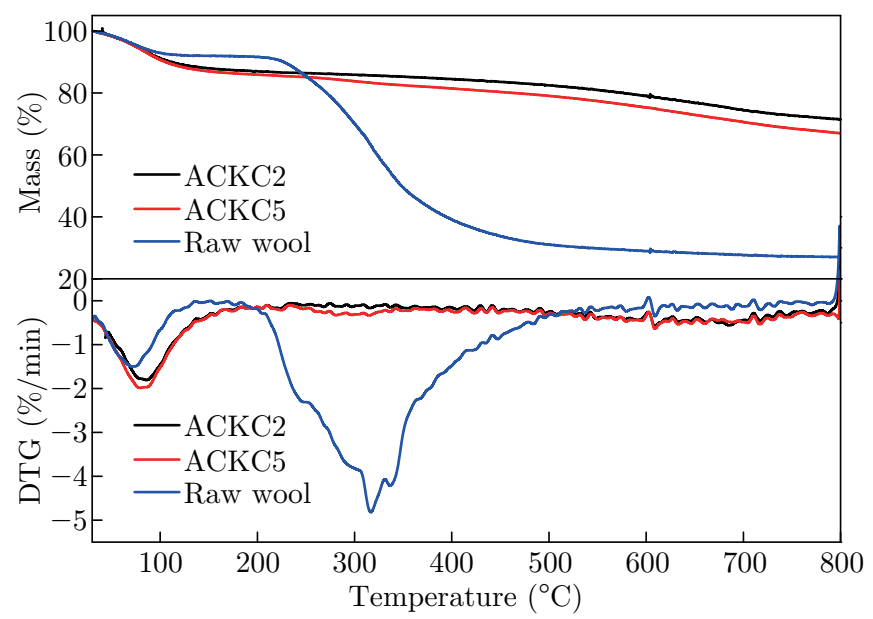

Fig. 3: Thermogravimetric analysis of: ACKC2; ACKC5; raw wool

\subsection{Methylene Blue (MB) Adsorption}

As is shown in Fig. 5, when ACTs under different conditions were placed in MB solution, the concentration of MB gradually decrease with time, all samples show the same trend. In the process of one-step, ACTs with or without scales by $20 \% \mathrm{~K}_{2} \mathrm{CO}_{3}$ under air or $\mathrm{N}_{2}$ flow shows the highest adsorption capacity in the fourth hour. From the MB adsorption isotherms, ACTs has limited adsorption capacity and its concentration becomes a constant at last. The adsorption performance of ACTs by two-step from $400{ }^{\circ} \mathrm{C}$ to $500{ }^{\circ} \mathrm{C}$ is basically the same and has not changed too much. However, when the activation temperature is $600{ }^{\circ} \mathrm{C}$, it is found that the effect of adsorption after 1 hour is very obvious. After 2 hours, the concentration of methylene solution is zero. It can

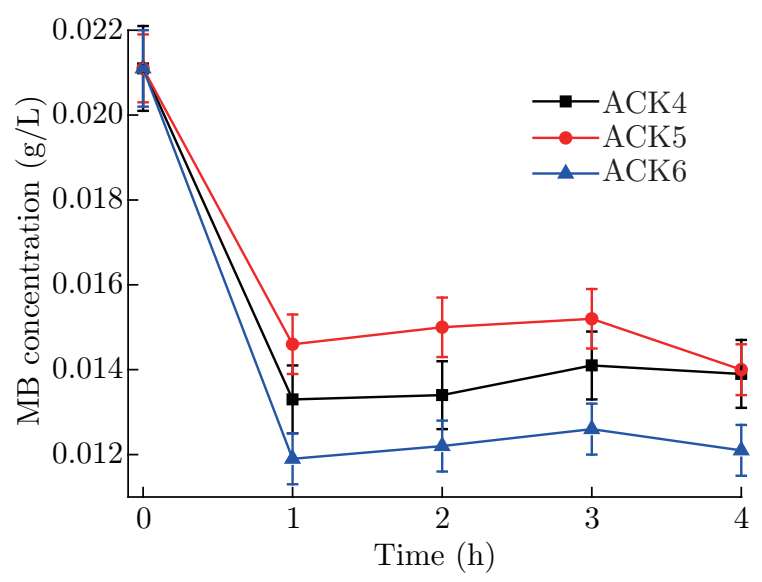

Fig. 4: Residual MB concentration for ACK4-6

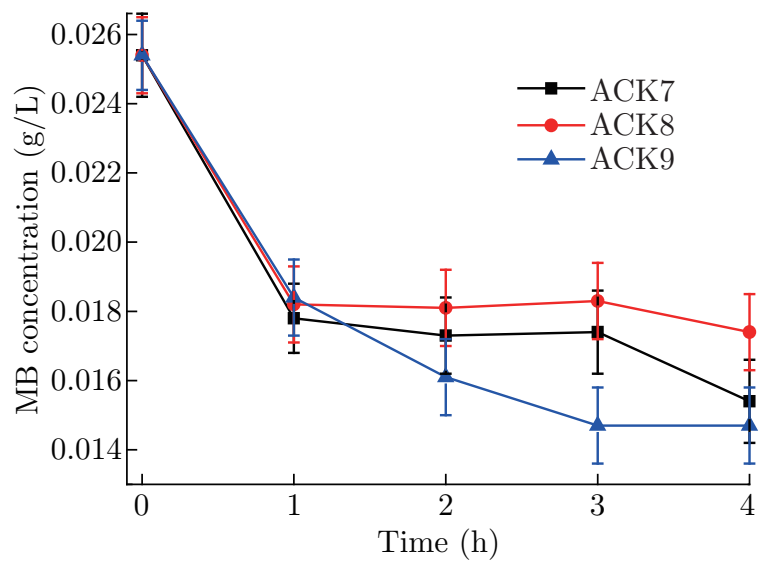

Fig. 5: Residual MB concentration for ACK7-9 
be inferred that the adsorption has been completed and the highest adsorption capacity is found from ACKC6 among all samples.

Fig. 4-7 shows the adsorbance of MB for ACTs, which is calculated from Lambert-Beer law Eq. The samples activated by one-step are much less effective than by two-step. Compared with the adsorbance of ACTs under $\mathrm{N}_{2}$ flow, the final residual MB concentration for ACTs under air is significantly lower, showing higher adsorption capacity. There is a strange phenomenon that the adsorption capacity of ACTs without scales activated by one-step is slightly lower than ACTs with scales, but it's opposite in two-step method.

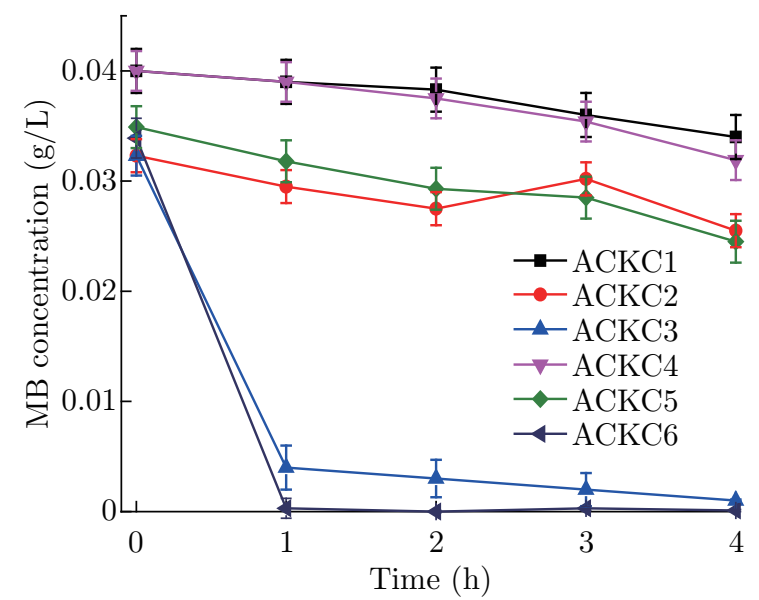

Fig. 6: Residual MB concentration for ACKC1-6

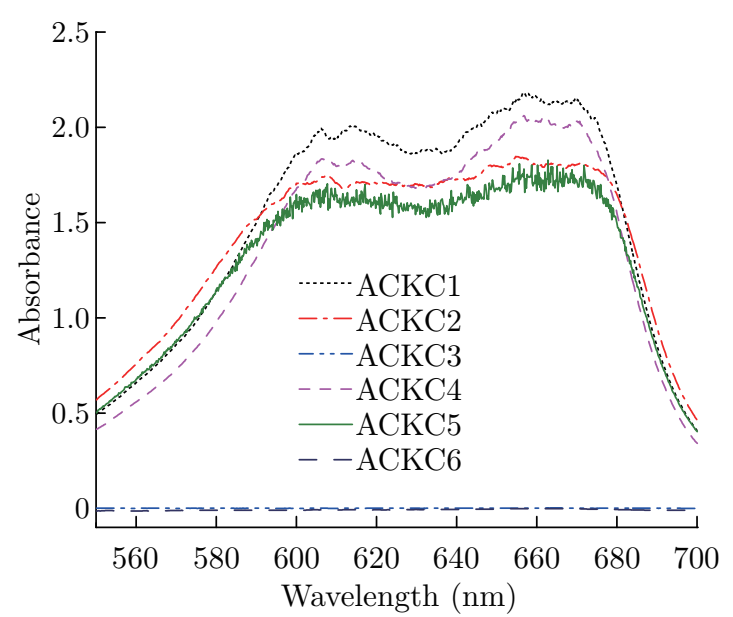

Fig. 7: Residual MB concentration for ACKC1-6

\section{Conclusion}

The ACTs can be prepared both from wool with or without scales, which proves that the existence of scale layer isn't the factor for the formation of unique tubular shape. The method of removing scales is to use formic acid treatment for 70 minutes combined with ultrasonic vibration treatment for 100 minutes, which has the best effect on scale stripping of wool. Scale layers have almost no effects on thermal decomposition because the values of weight loss were very close. Only under air condition, ACTs with tubes from wool can be prepared by one-step activation process, and the adsorption performance is better. So the ACTs can be obtained with no gas carrying, which could simplify the process and reduce the cost. In the one-step activation process, the adsorption property of ACTs made from wool with scales is slightly lower than that from raw wool, which may be due to the destruction of the surface structure of wool fiber by chemical treatment. In the two-step process, the adsorption values of ACTs rise obviously in the range of $80.50 \mathrm{mg} / \mathrm{g}$ to $84.00 \mathrm{mg} / \mathrm{g}$ with the increasing temperature, especially when reaches to $600{ }^{\circ} \mathrm{C}$, which means the temperature is the key factor to affect the adsorption properties.

\section{References}

[1] Kawano T, Kubota M, Onyango MS, et al. Preparation of activated carbon from petroleum coke by $\mathrm{KOH}$ chemical activation for adsorption heat pump. Applied Thermal Engineering: 2008, 28: 865-871. 
[2] Chowdhury ZZ, Zain SM, et al. Preparation, characterization and adsorption performance of the $\mathrm{KOH}$-activated carbons fibers derived from kenaf fiber for lead (II) removal from waste water. University Malaya: 2011, 6: 6185-6196.

[3] J.M. Rosas, J. Bedia, M.J. Rodriguez, T. Cordero, HEMP-derived activated carbon fibers by chemical activation with phosphoric acid. Fuel: 2009, 88: 19-26.

[4] Y. Zhao, F. Fang, H.M. Xiao, Q.P. Feng, L.Y. Xiong, S.Y. Fu, Preparation of pore-size controllable activated carbon fibers from bamboo fibers with superior performance for xenon storage. Chemical Engineering Journal: 2015, 270: 528-534.

[5] O. Pezoti, A.L. Cazetta, K.C. Bedin, L.S. Souza, A.C. Martins, NaOH-activated carbon of high surface area produced from guava seeds as a high-efficiency adsorbent for amoxicillin removal: Kinetic, isotherm and thermodynamic studies, Chemical Engineering Journal: 2016, 288: 778788.

[6] T. Otowa, Y. Nojima, T. Miyazaki, Development of KOH activated high surface area carbon and its application to drinking water purification. Carbon: 1997, 35: 1325-1329.

[7] S. Hu, S. Zhang, N. Pan, Y.L. Hsieh, High energy density supercapacitors from lignin derived submicron activated carbon fibers in aqueous electrolytes. Journal of Power Sources: 2014, 270: 106-112.

[8] Mialk PK. Dye removal from waste water using activated carbon developed from sawdust: adsorption equilibrium and kinetics. J Hazadr Mater: 2004, 113: 81-88.

[9] Lin T, Chen H, Hua W, et al. Study of activated carbon adsorption for bromate removal in drinking water treatment. J Huazhong University of science and technology: 2014, 05: 95-100.

[10] Zhen-yu L, Jing-tang Z, Mao-zhang W, et al. Nanostructure and analysis of porous carbon. Progress in chemistry: 2001, 13(1): 10-18

[11] Shui-xia C, Han-min Z. Progress on activated carbon fibers. Chinese Journal of Reactive Polymers: 2002, 11(2): 97-107.

[12] Qi-tao Z, Wen C, Zhong-hua L. Application and research progress of activated carbon. J Kunming University of science and technology: 2000, 26(3): 8-12.

[13] B.M. Chapman, A mechanical model for wool and other keratin fibres, Textile Research Journal, 1969 (39) 1102-1109.

[14] G. Wen, J.A. Rippon, P.R. Brady, X.G.Wang, X. Liu, P.G. Cookson. The characterization and chemical reactivity of powdered wool. Powder Technology: 2009, 193: 200-207.

[15] J.Y. Hu, Y. Li, Y.F. Chang, K.W. Yeung, C.W. Yuen. Transport properties of fabrics treated with nano-wool fibrous materials. Colloids and Surfaces A, Physicoche-Mical and Engineering Aspects: 2007, 300(1-2): 136-139.

[16] Y.F. Cheng, C.W.M. Yuen, Y. Li, S.K.A. Ku, C.W. Kan, J.Y. Hu. Characterization of nano scale wool particles. Journal of Applied Polymer Science: 2007, 104: 803-808.

[17] Miyamoto, T. Amiya, H. Inagaki. Preparation of wool powder by explosivepu-ffing tratmente. Kobunshi Ronbunshu: 1982, 39(11): 679-685.

[18] W. Xu, X. Wang, W. Li, X. Peng, X. Liu, X. Wang. Characterization of superfine wool powder poly(propylene) blend film. Macromolecular Materials and Engineering: 2007, 674-680.

[19] Shang-yu G editor. Foundation and application of activated carbon. China Forestry press, 1984. 